\title{
62. Über die Farbenreaktion von Fluoren, Inden etc.
}

\author{
Von Takaoki SASAKI, M.I.A. \\ Aus dem Sasaki-Laboratorium zu Tokyo. \\ (Comm. July 12, 1941.)
}

Bei Gelegenheit der Durchforschung von sog. carcinogenen Substanzen fand Sasaki, dass Fluoren und Inden durch Zusatz der alkoholischen Pikrinsäurelösung und Alkali eine intensive rote Pikrinsäurereaktion zeigen. Die Reaktion ist insoweit von präparativ-chemischer Bedeutung, da sie nach seiner Meinung das Vorhandensein des sog. beweglichen, reaktionsfähige Methylwasserstoffes darstellt $t^{1}$. Infolge des Erfinden derselben Reaktion mit Diketopiperazin baute Sasaki in der Tat seine Glycinanhydridmethode der Aminosäure-synthese's) auf. Bekanntlich gründet sich auch Friedländersche Chinolinsynthese auf Kondensation von o-Aminobenzaldehyd mit einer carbonylbenachbarten, beweglichen Methylengruppe enthaltenden Substanzen. Bisher gefundene die Pikrinsäurereaktion zeigende Substanzen haben meist Carbonylgruppe in ihrem Molekül ${ }^{3)}$. Sie stimmt aber nicht immer mit der von Alters her von Organiker gebräuchlich genannte "Carbonylreaktion". Andererseits haben einige Substanzen, welche die Carbonylreaktion im gebräuchlichen Sinne geben, keine Pikrinsäurereaktion; so z. B. Benzaldehyd.

Fluoren und Inden haben gar keine Carbonylgruppe in ihrem Molekül. Doch haben sie eine intensive Pikrinsäurereaktion. Die beiden Substanzen haben bekanntlich eine reaktionsfähige Methylengruppe in ihren Molekülen, welche so z. B. mit Aldehyd etc. leicht in Kondensation eingeht. Somit wurde erwiesen, dass die Substanz mit einer beweglichen Methylgruppe ohne Carbonyl auch die Pikrinsäurereaktion zeigt.

Bemerkenswert ist, dass Diphenylmethan, das nach intramolekularer Ringschliessung in Fluoren übergeht, keine Pikrinsäurereaktion hat. Mit Cyclopentadien tritt sie nach Sättigen mit Brom auch stark auf.

1) T. Sasaki : Biochem. Ztschr. 114 (1921), 63.

2) T. Sasaki : Ber. Dtsch. chem. Ges. 54 (1921), 163.

3) Vgl. E. Abderhalden u. E. Komm: Ztschr. physiol. Chem. 139 (1924), 181. ebenda 140 (1924), 99. 